\title{
Bentonite reactivity in alkaline solutions: interim results of the Cyprus Natural Analogue Project (CNAP)
}

\author{
W. R. ALEXANDER ${ }^{1, *}$,A. E. MILODOWSKI ${ }^{2}, A$. F. PITTY ${ }^{3}$, \\ S. M. L. HARDIE ${ }^{4}$ S. J. KEMP ${ }^{2}$, J. C. RUSHTON ${ }^{2}$, ANDREAS SIATHAS ${ }^{5}$, \\ AVRIM SIATHAS ${ }^{5}$, A. B. MACKENZIE ${ }^{6}$, P. KORKEAKOSKI ${ }^{7}$, S. NORRIS $^{8}$, \\ P. SELLIN ${ }^{9}$ AND M. RIGAS ${ }^{10}$ \\ ${ }^{1}$ Bedrock Geosciences, Auenstein, Switzerland, ${ }^{2}$ British Geological Survey, Keyworth, UK, ${ }^{3}$ Pitty (EIA) Consulting, \\ Norwich, UK, ${ }^{4}$ Scottish Universities Environmental Research Centre (SUERC), East Kilbride, UK (current address \\ MCM International, Baden-Dättwil, Switzerland), ${ }^{5}$ Geoinvest Ltd., Aglantzia, Cyprus, ${ }^{6}$ SUERC, East Kilbride, UK, \\ ${ }^{7}$ Posiva, Olkiluoto, Finland, ${ }^{8}$ NDA-RWMD, Harwell, UK, ${ }^{9}$ SKB, Stockholm, Sweden, and \\ ${ }^{10}$ Geological Survey Department, Strovolos, Cyprus
}

(Received 4 December 2012; revised 12 March 2013; Editor: John Adams)

\begin{abstract}
Bentonite is one of the more safety-critical components of the engineered barrier system in the disposal concepts developed for many types of radioactive waste. It is used due to its favourable properties (including plasticity, swelling capacity, colloid filtration, low hydraulic conductivity, high retardation of key radionuclides) and its stability in relevant geological environments. However, bentonite is unstable under alkaline conditions and this has driven interest in low-alkali cements (leachate $\mathrm{pH}$ of $10-11$ ). To build a robust safety case, it is important to have supporting natural analogue data to confirm understanding of the likely long-term performance of bentonite. In Cyprus, the presence of natural bentonite in close proximity to natural alkaline groundwaters permits the zones of potential bentonite/alkaline water reaction to be studied as an analogy of the potential reaction zones in the repository. Here, the results indicate minimal volumetric reaction of bentonite, with production of a palygorskite secondary phase.
\end{abstract}

KEYwORDs: bentonite buffer, alteration, natural analogue, Cyprus, CNAP.

Bentonite makes an important contribution to the performance of the engineered barrier system (EBS) for the disposal concepts developed for many types of radioactive waste. The choice of bentonite results from its favourable properties for isolation and containment of the waste - plasticity, swelling capacity, colloid filtration, low hydraulic conductivity, high retardation of key radionuclides - and its stability in relevant geological environments. According to NDA (2010), the most important

* E-mail: russell@bedrock-geosciences.com

DOI: $10.1180 /$ claymin.2013.048.2.06 processes which could impact the bentonite's safety functions are:

Diffusive transport of cement leachates into the bentonite: sharp gradients in $\mathrm{pH}$ (and $p \mathrm{CO}_{2}$ ) across the interface would encourage rapid precipitation of solid carbonates (e.g. aragonite) and hydroxides (e.g. brucite), leading to a decrease in porosity;

(1) Fast exchange of cations in cement leachates for cations in montmorillonite interlayer sites, leading to a decrease of swelling pressure;

(2) Slow dissolution of montmorillonite and other minerals (e.g. quartz, feldspar). At elevated $\mathrm{pH}$, such reactions consume hydroxyl ions, thus neutralising the incoming cement leachates. In this case, this leads to an increase in porosity and may 
decrease the bentonite swelling pressure due to mass loss.

This led to some repository designs (especially for disposal of high-level vitrified waste, HLW or spent fuel, SF) that exclude concrete from any sensitive areas containing bentonite, so avoiding any potential bentonite degradation in the case that it is contacted by cementitious porewaters (which have an initial $\mathrm{pH}$ of $>13$ ) which leach of out any concrete used in the repository.

The MX-80 bentonite, for example, has been shown to have a porewater $\mathrm{pH}$ of 8 in ambient groundwaters (Bradbury \& Baeyens, 2002), significantly less than that of low-alkali cement leachates with a $\mathrm{pH}$ of 11 or less (e.g. Savage \& Benbow, 2007). Sellin et al. (2003) noted that the dissolution rate for a number of aluminosilicates increases by a factor of 10 if $\mathrm{pH}$ is increased from 11 to 13 and more recent work (e.g. Rozalen et al., 2009) indicate that bentonite is much more stable at $\mathrm{pH} 11$ than $\mathrm{pH} 13$.

Recently, therefore, there have been extensive efforts to understand better the interactions of alkaline fluids with bentonite (cf. Wilson et al., 2011), coupled with studies aimed at reducing the risk by development and testing (e.g. Alonso et al., 2009) of low-alkali cement formulations. The greatest challenge is bringing the information produced by laboratory and modelling studies together to form a robust safety case for a geological repository for radioactive waste. This is complicated by the inherently slow kinetics of such reactions (e.g. Heikola et al., 2013) and the commonly observed persistence of metastable phases for geological time periods (for a good overview of the issues involved see Metcalfe \& Walker, 2004). Clearly, this is an area where natural analogues (NA) could play a valuable role - bridging the disparity in realism and timescales between laboratory studies and the systems represented in repository safety assessment (SA). Indeed, the particularly slow kinetics of bentonite reaction in low alkali cement porewaters ${ }^{1}$ suggests NAs are the only viable method of studying bentonite reaction within reasonable timescales which would allow input to current SA.

\section{THE NATURAL ANALOGUE CONCEPT}

For the specific case of radioactive waste management, the term NA has developed a particular meaning associated with supporting arguments for the long-term safety of repositories. Key factors are the heterogeneity and complexity of natural systems and, in particular, the very long timescales over which safety must be assured; for a more detailed discussion of the uses of NA in waste disposal see Chapman et al. (1984), Miller et al. (2000) and Alexander et al. (2013).

In this study, the island of Cyprus (Fig. 1) was proposed as the focus primarily due to the known widespread occurrence of both alkaline groundwaters (resulting from serpentinization of the Troodos ophiolite; e.g. Neal \& Shand, 2002) and extensive bentonite deposits (e.g. Bear, 1960). The details of the production of the alkaline groundwaters is discussed in Alexander et al. (2011). Here it is sufficient to note that the chemistry of the natural groundwaters is similar enough to the leachates of low alkali cements to make this a viable NA.

\section{SITE DESCRIPTION}

Although a suite of sites was examined during the study (full details in Alexander \& Milodowski, 2013), the main focus was on the area around Parsata. This abandoned village sits on a wide plateau above the Vasilikos valley, just north of the town of Limassol (Fig. 1). The area offered the ideal combination of appropriate alkaline groundwaters in contact with bentonite and preliminary analysis of rock samples had shown abundant smectite and evidence of both inactive and currently active groundwater flow systems. The bentonites are from the Perapedhi Formation and are distributed over the palaeo-depressions in the Upper Pillow Lavas (UPL) as lenses of various thickness. The UPL were deeply weathered in the submarine environment before the bentonites were laid down, but have also been extensively faulted since. It quickly became clear that large areas of the Vasilikos valley have suffered bentonite debris flow

1 The conclusions to the ECOCLAY-II project (ECOCLAY, 2005) note that "In the case of highly compacted bentonite, the experiments carried out in the project indicate that the high $\mathrm{pH}$ front inducing mineral reactions on the smectite does not penetrate further than $5 \mathrm{~cm}$, and the portlandite front with lower $\mathrm{pH}$ not further than $10-20 \mathrm{~cm}$ within a very long time span, up to 100000 years." 


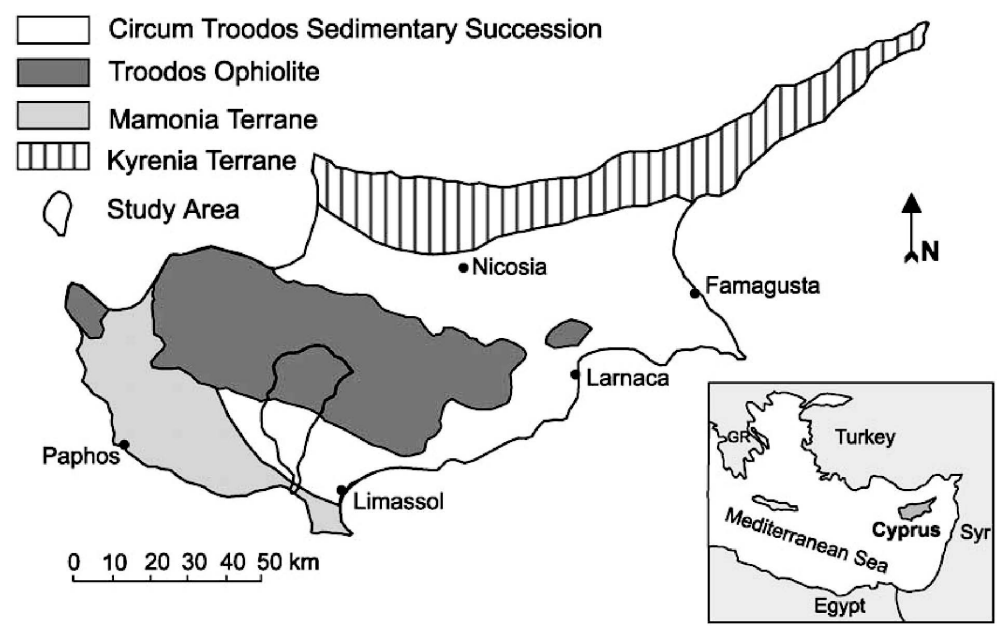

FIG. 1. Main geological terrains in Cyprus (from Boronina et al., 2005).

and these generally rafted down bentonites and chalks of the overlying Kannaviou and Lower Lefkara Formations respectively.

Over two field seasons at the Parsata site, a geomorphological analysis was carried out, ground penetrating radar and resistivity studies were conducted, four shallow boreholes were drilled and five trenches excavated in an area $150 \mathrm{~m}$ to the SW of the village. In addition, five boreholes around the site were sampled for groundwaters. Although no groundwaters were encountered in the site boreholes, the bases of Trenches 1 and 4 were noticeably damp upon excavation, although the $\mathrm{pH}$ of the moisture could not be ascertained.

\section{SAMPLING AND ANALYTICAL DET A ILS}

Full sampling and analytical information is provided in great detail in Alexander \& Milodowski (2011, 2013) and Alexander et al. (2011). Briefly, groundwater samples were pumped from various wells and sub-sampled, fixed and stored according to BGS (British Geological Survey) standard groundwater handling techniques. Analysis of the groundwater samples was carried out in the Analytical Geochemistry Laboratories of BGS and natural decay series radionuclides were analysed in the laboratories of SUERC (Scottish Universities Environmental Research Centre).

Solid phase samples were collected by a combination of drilling (rock chip logging and coring) and trenching (sampling along profiles on the trench faces and bases). A suite of 90 samples was selected to represent the bentonite profiles from the trenches and boreholes and submitted to the BGS laboratories for whole-rock and clay mineralogical analysis by X-ray diffraction (XRD) and major and trace element geochemistry by X-ray fluorescence spectroscopy (XRF). A sub-set of samples was selected for detailed petrographic analysis on polished sections by scanning electron microprobe (SEM) and whole-sample chemical compositions of rocks and soil samples were determined by XRF. A sub-set of samples was also selected for natural decay series analyses in the laboratories of SUERC. A final sub-set of samples was selected for determination of the physical properties of the bentonite in the laboratories of Geoinvest Ltd.

\section{RESULTS}

\section{Groundwaters}

The groundwater analyses are provided in Table 1 and are discussed below.

\section{Major and trace elements}

The Allas (A) and Chrysovrysi Springs (C) have previously been identified as alkaline groundwaters (Neal \& Shand, 2002) and their major element chemistry is typical for the ophiolite-sourced groundwaters in Cyprus. Being open springs, most show some form of reaction with uptake of atmospheric $\mathrm{CO}_{2}$ (with precipitation of copious 
TABLE 1. Selected major element concentrations for selected groundwater samples (all concentrations $\mathrm{mg}^{-1}$ ). $\mathrm{P}$ $=$ Parsata, A = Allas Springs, $\mathrm{C}=$ Chysovrysi Springs (data from, and full details of all sites in, Alexander et al., 2011; Alexander \& Milodowski, 2013).

\begin{tabular}{lccccccccccc}
\hline Sample & $\begin{array}{c}\text { Field } \\
\mathrm{pH}\end{array}$ & $\mathrm{Lab} \mathrm{pH}$ & $\mathrm{Ca}^{2+}$ & $\mathrm{Mg}^{2+}$ & $\mathrm{Na}^{+}$ & $\mathrm{K}^{+}$ & $\mathrm{CO}_{3}^{2-}$ & $\mathrm{HCO}_{3}^{-}$ & $\mathrm{Cl}^{-}$ & $\mathrm{SO}_{4}^{2-}$ & $\mathrm{NO}_{3}^{-}$ \\
\hline P1-2010a & 11.1 & n.d. & 48.3 & 0.11 & 96.5 & 1.34 & 5.40 & n.d. & 80.9 & 149 & $<0.200$ \\
P1-2012 & 10.9 & n.d & 49.8 & 0.04 & 110 & 1.10 & 6.04 & $<5.00$ & 86.0 & 156 & 0.101 \\
A4-1 & n.d. & 9.77 & 3.20 & 58.7 & 747 & 31.4 & 127 & 152 & 1093 & 87.2 & 0.343 \\
A1-1 & 11.9 & 11.3 & 37.2 & 0.101 & 1435 & 63.1 & n.d. & 272 & 2177 & 101 & $<1.5$ \\
A1-3 & 10.01 & 9.31 & 12.2 & 0.554 & 1337 & 60.1 & 54.1 & 96.4 & 1926 & 114 & 10.3 \\
C2 & 9.58 & 8.90 & 1.69 & 67.9 & 4.79 & $<0.5$ & 23.7 & 255 & 8.361 & 3.207 & 0.580 \\
C1 & 9.41 & 8.85 & 1.80 & 68.3 & 4.68 & $<0.5$ & n.d. & 309 & 8.486 & 3.272 & 0.640 \\
C3 & 9.69 & 9.11 & 1.67 & 92.7 & 5.14 & 0.926 & 44.5 & 311 & 18.2 & 2.484 & 1.86 \\
& & & & & & & & & & & \\
\hline
\end{tabular}

tufa around the springs), but the $\mathrm{pH}$ of sample A1-1 is unusually high as it was collected directly as it left a fracture in gabbro high on the Troodos Massif. The P1 samples come from groundwater below the bentonite (at the Parsata Almond Orchard borehole) and, from the borehole depth, the sampling interval is in the altered UPL. The field $\mathrm{pH}$ of 11.1, high $\mathrm{Ca}$ and low $\mathrm{Fe}, \mathrm{Mn}$ and $\mathrm{CO}_{3}$ concentrations are all indicative of little or no reaction with the atmosphere. Although ophiolite groundwater chemistry does vary significantly from one ophiolite to another (cf. Barnes \& O’Neill, 1969), borehole P1 stands out significantly from all the other Cyprus samples in having very low $\mathrm{K}$ and $\mathrm{Mg}$ concentrations.

The P1 stable isotope signature suggests infiltration some 200-300 $\mathrm{m}$ above the borehole, implying relatively local input on the ridge immediately above the village.

\section{Bentonite}

The information supplied here is a brief summary of the full data set which is available in Alexander et al. (2011) and Alexander \& Milodowski (2011,
2013). Clearly the industrial bentonites which are employed as part of the EBS of a repository are heavily processed (cf. Neaman et al., 2003) and so are somewhat different from the natural bentonites described here. Neverthless, determination of a range of physico-chemical properties of the material sampled at Parsata will allow an estimation of how close an analogy may be drawn and, subsequently, how valuable are the data for a repository SA.

\section{Physical properties}

Here, a suite of analyses of the physical properties of the bentonite were carried out and the results are presented in Table 2. For comparison, Posiva's guidelines for bentonite quality assurance (Ahonen et al., 2008) are also presented.

It can be seen that, despite the non-processed nature of the natural bentonite, most of the parameters fall within or are close to Posiva's guideline values for the industrial bentonite. Only in swelling pressure is there a significant deviation with the natural bentonites displaying a much lower capacity to swell.

TABLE 2. Values for some selected physical parameters of the CNAP natural bentonites compared with Posiva's guidelines (Ahonen et al., 2008) for industrial bentonites for a repository (Alexander \& Milodowski, 2013).

\begin{tabular}{lccccc}
\hline Parameter & $\begin{array}{c}\text { Water content } \\
(\%)\end{array}$ & $\begin{array}{c}\text { Smectite content } \\
(\text { wt. \%) }\end{array}$ & $\begin{array}{c}\text { Liquid limit } \\
(\%)\end{array}$ & $\begin{array}{c}\text { CEC } \\
\left(\mathrm{mEq} \mathrm{100} \mathrm{g}^{-1}\right)\end{array}$ & $\begin{array}{c}\text { Swelling pressure } \\
(\mathrm{Mpa})\end{array}$ \\
\hline Posiva guidelines & $<13$ & $>75$ & $>80$ & $>60$ & $1-10$ \\
CNAP Trench 4 & $18-25$ & $26-50$ & $74-89$ & $47-59$ & $0.09-0.14$ \\
CNAP Trench 5 & $17-23$ & $24-28$ & $106-131$ & $34-43$ & $0.12-0.17$ \\
\hline
\end{tabular}




\section{Whole-rock analysis}

The results of quantitative whole-rock XRD analyses and the general distribution of the amorphous and major crystalline phases are illustrated in Fig. 2. Errors for the quoted mineral concentrations are typically $\pm 2.5 \%$ (for concentrations $>60$ wt. $\%$ ), increasing to $\pm 40 \%$ for concentrations $<3$ wt.\% (Hillier et al., 2001). Where a phase was detected, but its concentration was indicated to be below $0.5 \mathrm{wt} \%$, it is assigned a value of $<0.5$ wt. $\%$, since the error associated with quantification at such low levels becomes too large.

The samples are predominantly composed of smectite (10 to $40 \%)$, cristobalite $(<0.5$ to $45.5 \%)$, quartz ( 0.6 to $16 \%)$, zeolites $(<0.5$ to $15 \%)$, plagioclase feldspar $(<0.5$ to $12 \%)$ and 'mica' (undifferentiated mica species possibly including muscovite, biotite, illite, illite/smectite, $<0.5$ to $6 \%$ ) \pm calcite, pyroxene, palygorskite, manganite, goethite, pyrite, pyrolusite, chlorite, hematite and amphibole. Quantitative XRD also suggest that the samples contain a significant amount of X-ray amorphous material (19 to 53\%) which SEM analysis indicated to be predominantly amorphous silica (from tests). Although the amorphous content shows no apparent systematic variation with borehole/trench depth, it appears to generally correspond with the smectite content.

XRD analysis (Fig. 3) suggests that the clay mineral assemblages of the samples are predominantly composed of smectite together with minor amounts of palygorskite and illite and traces of chlorite. In all cases, the separated $<2 \mu \mathrm{m}$ fractions also contain a variety of non-clay minerals including quartz, albite, zeolites and calcite. In the Parsata 1 and 2 boreholes, the clay mineral assemblages show little overall variation except for a minor decrease in smectite and the removal of trace quantities of chlorite with increasing depth that corresponds with an increase in illite.
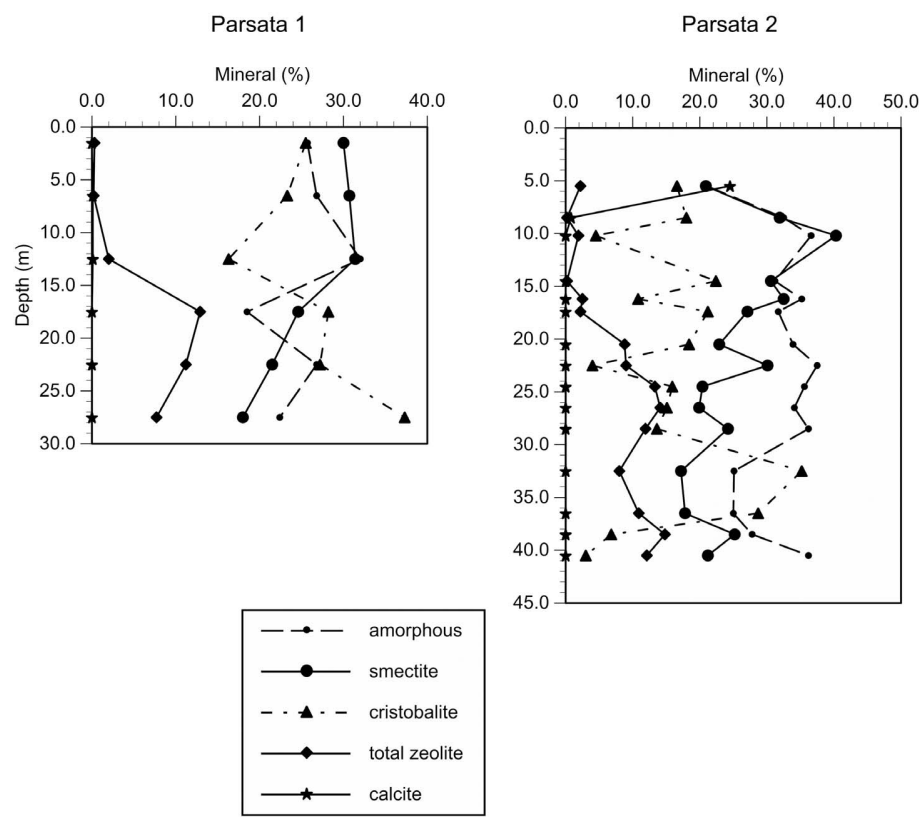

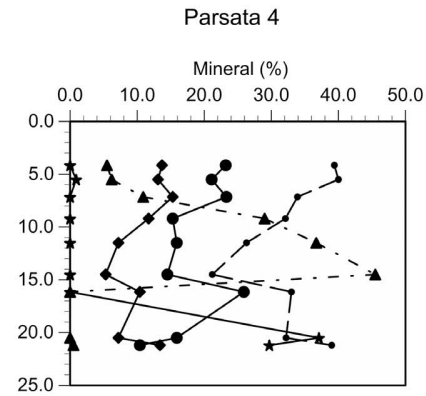

Pit 1

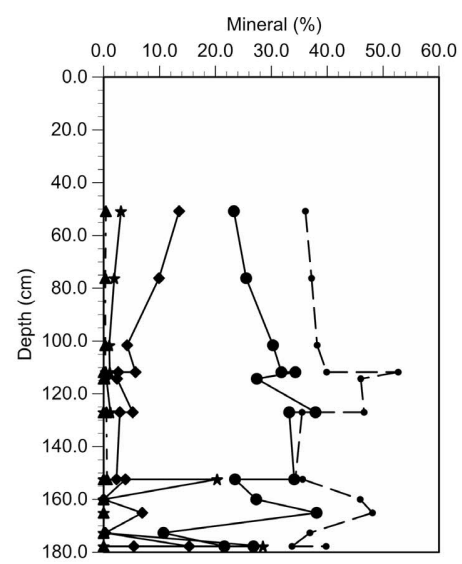

FIG. 2. Downhole variation in major mineral species, Parsata boreholes and Trench 1 (Alexander et al., 2011). 


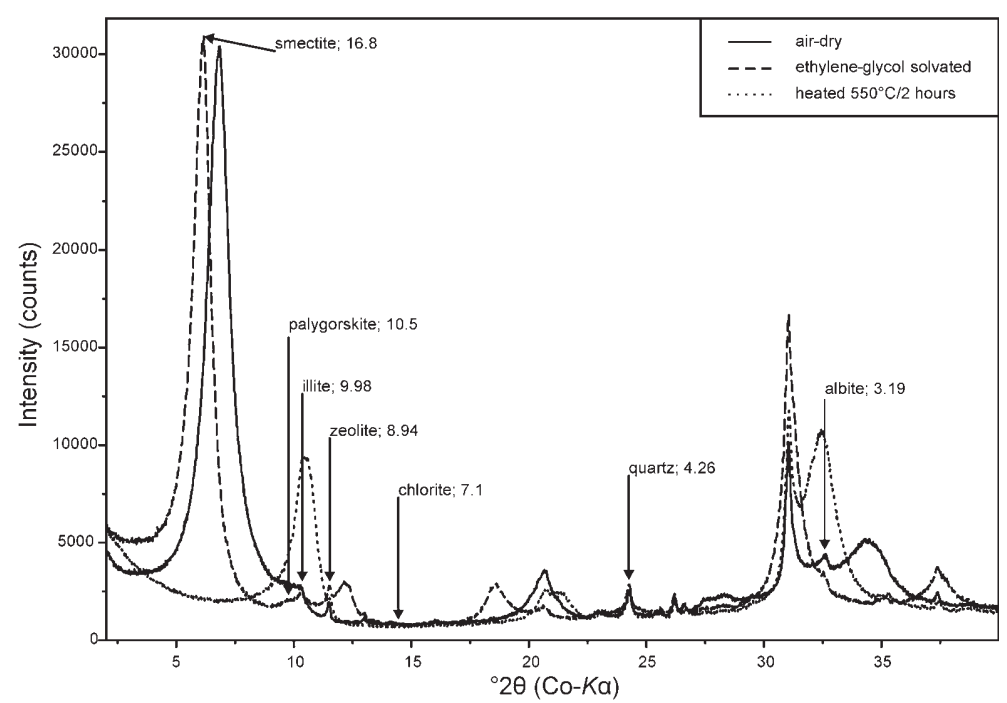

FIG. 3. Example $<2 \mu \mathrm{m}$ XRD traces to illustrate the typical clay mineral assemblage, solid trace (air dry), dashed trace (glycol-solvated), dotted trace (heated $550^{\circ} \mathrm{C}$ for $2 \mathrm{~h}$ ), sample T4-26 (Alexander \& Milodowski, 2013).

\section{PETROGRAPHICAL RESULTS}

The examined sample suite comprises a mix of bentonite and variably altered UPL, but the former are the primary interest in this study. The nature of fractures in the bentonites, their deposits and the properties of their host materials are also summarized. Finally, an interpretive paragentic sequence is proposed.

\section{Bentonites}

The sediments that have been included in this section are considered to be marginal as to their nomenclature (between mud and bentonite), having some degree of plasticity when still damp but also being moderately consolidated. Of the primary constituents, detrital clays are the dominant constituent of these sediments, which are all matrix-supported. Where not obscured by secondary phases, these are observable as platy phases with the rough and ragged edges typical of detrital clay minerals (Fig. 4). They are tightly packed and compositions derived from small area average SEM EDXA (Energy Dispersive X-ray spectroscopy) analyses are consistent with these being dominantly di-octahedral smectites.

Variable proportions of other primary phases are present, as clay-grade sediment, and as silt and rarely sand grains. Scarce identifiable bioclasts are dominantly silica-based planktonic debris (diatoms, spicules); these are typically altered/recrystallized. Plant debris and limestone fragments are other rare constituents. Several samples have significant contents of probable volcaniclastic fragments, mainly pyroclastic fiamme (i.e. flame-like glasses)

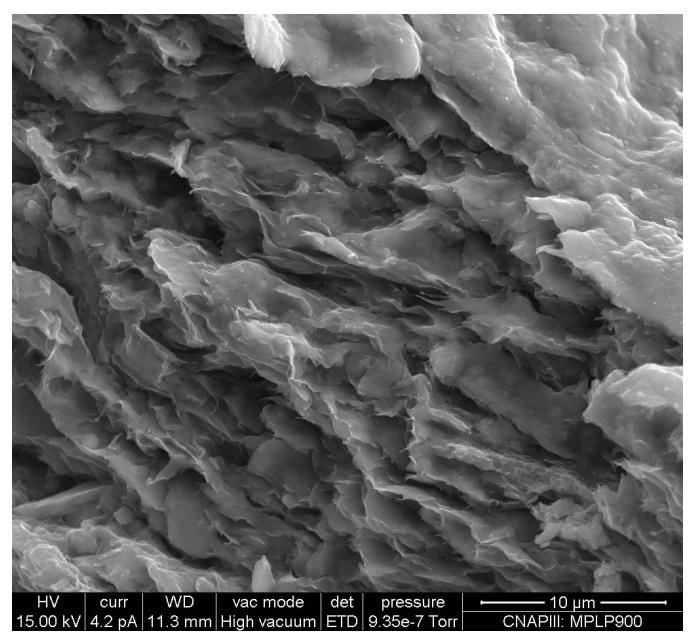

FIG. 4. SEM image, sample MPLP900, C-coated rock chip. Typical clay matrix textures (adjacent to a fracture). The matrix clays are predominantly platy with widespread secondary webbed and fibrous margins (Alexander et al., 2011). 
fragments, including some very fine grained 'microfiamme' (Fig. 5).

Secondary minerals are those formed postsedimentation through alteration of the primary constituents or through neoformation. In the Parsata bentonite, the main secondary mineral phases identified are:

(1) Clay minerals associated with matrix clays and through alteration of detrital clasts (e.g. pyroclastic fragments)

(2) Zeolites, analcite

(3) Feldspars, silica phases

(4) Mn and Fe oxides/hydroxides

(5) Calcium carbonate

(6) Calcium sulfate

The secondary clay minerals are primarily identified as such through their distinctive morphologies. In association with detrital clays, these are mainly finely webbed forms and fine fibres. The former are common throughout the matrix at detrital plate margins (possible alteration of the detrital host, or as a fresh secondary 'overgrowth'), also coating and bridging between other detrital and secondary constituents. Fibrous forms are widespread, also coating and bridging between detrital and secondary constituents, notably extending from detrital and secondary clay edges. Altered pyroclastic fragments primarily comprise a matted and extending fibrous phase. Both qualitative and

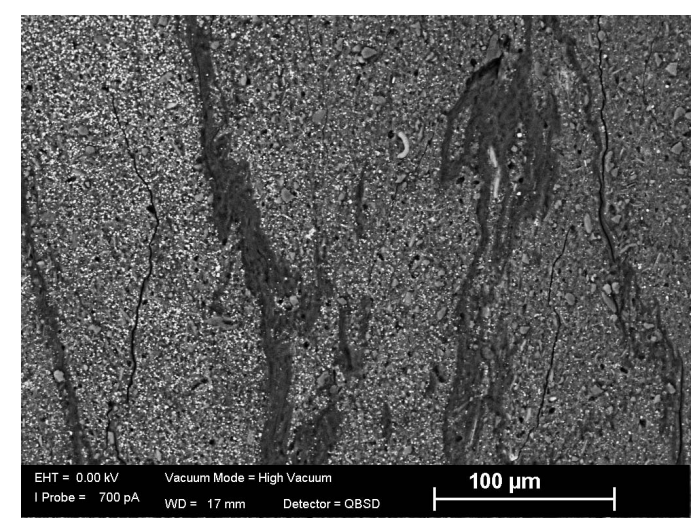

FIG. 5. BSE (Back-Scattered Electron) SEM image, Sample MPLP972, C-coated PTS. Fiamme textures are defined by darker areas. These now comprise alteration products (EDXA-derived compositions are consistent with palygorskite). A Mn-rich phase is identifiable as the high brightness specks (Mn-rich label is in a concentration of these). Alexander et al. (2011). quantitative EDXA-derived compositions suggest that this phase is an iron-bearing palygorskite.

The constituents associated with the matrix clays are very finely developed and typically intimately associated with other constituents, so no reliable EDXA-derived compositions could be obtained to aid in their identification. From morphology alone, the webbed and fibrous forms are potentially smectites and palygorskite respectively. The latter identification is supported by the similar morphology of the pyroclastic fragment alteration products and the fact that local fibre clusters within the matrix have qualitatively similar EDXA-derived compositions to those reaction products.

Zeolites (typically clinoptilolite/heulandite and rare stilbite) are widespread secondary phases, present in nearly all the samples, primarily scattered throughout the matrix clays, also in secondary pores and associated with altered grains. Possible analcime has also been identified, typically alongside and with a similar distribution to zeolites. Secondary K-feldspar and albite are rare phases, both present in the matrix and both partially coated by secondary clays.

Manganese phases (typically manganite) are common in some samples; in most samples, their distribution is strongly related to fractures, although only present in some fractures (cf. Alexander et al., 2008). Iron oxide/hydroxide phases are widespread throughout the bentonite, probably as iron III phases which are finely (and unidentifiably) dispersed throughout the matrix.

Fractures are discernible through the presence of a number of deposits that have formed along fractures, also through textures at fracture surfaces. This would suggest that the fractures represent the principal vertical pathways for groundwater transport as petrographical observations show that the matrix is dominated by sub-micron-scale microporosity, with little interconneced macroporosity. Therefore, groundwater and solute transport through the matrix of the rock is likely to be dominated by diffusive transport, with potentially advective flow through the fractures. Three main phases are present as fracture deposits: calcium carbonate, calcium sulfate and manganese phases.

Many of the bentonite fractures are marked by the presence of surface striations. These are variably developed, from just discernible to well developed on near-planar surfaces. Many of these surfaces have fine secondary webbed (probable) clay mineral developments that bridge across striae, suggesting clay formation in part post-dates the last 


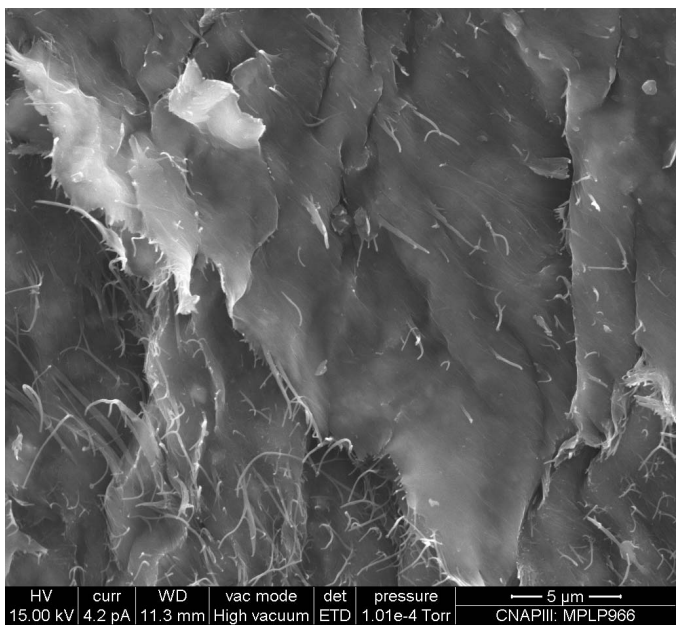

FIG. 6. SEM image, sample MPLP966, C-coated rock chip. A typical fracture surface has a smooth surface that comprises matted fibres roughly aligned with fracture-related striations (centre, upper right areas of image). Fibrous constituents (presumed to be palygorskite) are also common in the patch of sediment exposed in the lower left corner (Alexander et al., 2011).

significant fracture movement. Many have high contents, compared to the adjacent sediment matrix, of a fibrous phase morphologically and compositionally (qualitatively EDXA-derived) similar to palygorskite (Fig. 6). Fibres are commonly aligned parallel to striae. In comparison, zeolite exposed at a fracture surface that is itself striated, shows that the zeolite pre-dates the fracture movement.

In the sediment matrix adjacent to those fractures nearer the contact between the bentonite and the UPL, the webbed and fibrous secondary developments are more abundant adjacent to fractures than at some distance from them (on a scale of $\mathrm{mm}$ ). Looking in detail at material along the fracture faces (Fig. 7), it appears that the secondary phase is limited to a very narrow zone on and directly behind the fracture face.

\section{Clay chemistry}

Here, the results of the microchemical SEM EDXA analyses performed on the clay minerals of the matrix and altered detrital grains of the sedimentary samples from the Parsata site are considered. Quantitative analyses were typically recorded from small areas of the clay matrix of these samples, with sites being selected so as to minimize contamination by other sample phases (e.g. zeolites, etc). Where fractures were identified within a polished section, analytical sites were selected from fracture wall clays along the length of the fracture and from clay matrix at measured distances from the fracture. Point and small area analyses were also performed on some of the clayaltered detrital clasts. Triaxial plots are used to aid in the identification of any mineralogical, structural or compositional variations.

Figure 8 is a useful guide to mineral identification and it shows that the bulk of the data plots around the end-member montmorillonite point. Two data 'tails' are towards the end-member palygorskite and towards the apex of the $\mathrm{Si}$ axis. The palygorskite tail is shown most strongly in the altered grains, with the most palygorskite-like compositions coming from altered fiamme structures (e.g. sample MPLP901, Fig. 9). It is possible that the tail on the $\mathrm{Si}$ axis results from unresolved Si-rich amorphous material intermixed with the clays, probably related to dissolution of abundant radiolarian frustules (cf. Christidis, 2006). Si 'oversaturation' is certainly indicated in the compositional data from some of these points with $\mathrm{Si}$ APFU values of $>8$ resulting from some analyses. Consequently, the data plot is consistent with a clay mineral assemblage dominated by dioctahedral smectites and palygorskite, with the latter largely resulting from the post-depositional alteration of grains. Petrographic analysis shows that the bulk of the altered grains were originally volcaniclastic (e.g. fiamme structures - see Fig. 9) which altered to smectite and then subsequently to palygorskite.

Secondary grains have been identified and analysed in three samples (MPLP901, MPLP962 and MPLP963). Most are in the MPLP901 (altered fiamme) and MPLP962 (altered crystals and other grains in a crystal tuff) samples. All of the altered grain compositions plot on the mixing line between the end-member points for palygorskite and the dioctahedral smectites in the Si-octahedral cationsinterlayer cations plot (cf. Fig. 8).

Alteration products in MPLP901 are dominated by clays with palygorskite-like compositions and morphologies (fibrous and matted fibrous). Alteration products in MPLP962 are dominated by clays with smectite-like compositions and morphologies (webbed form), with a suggestion of a lesser intermixed palygorskite-like phase. These composi- 

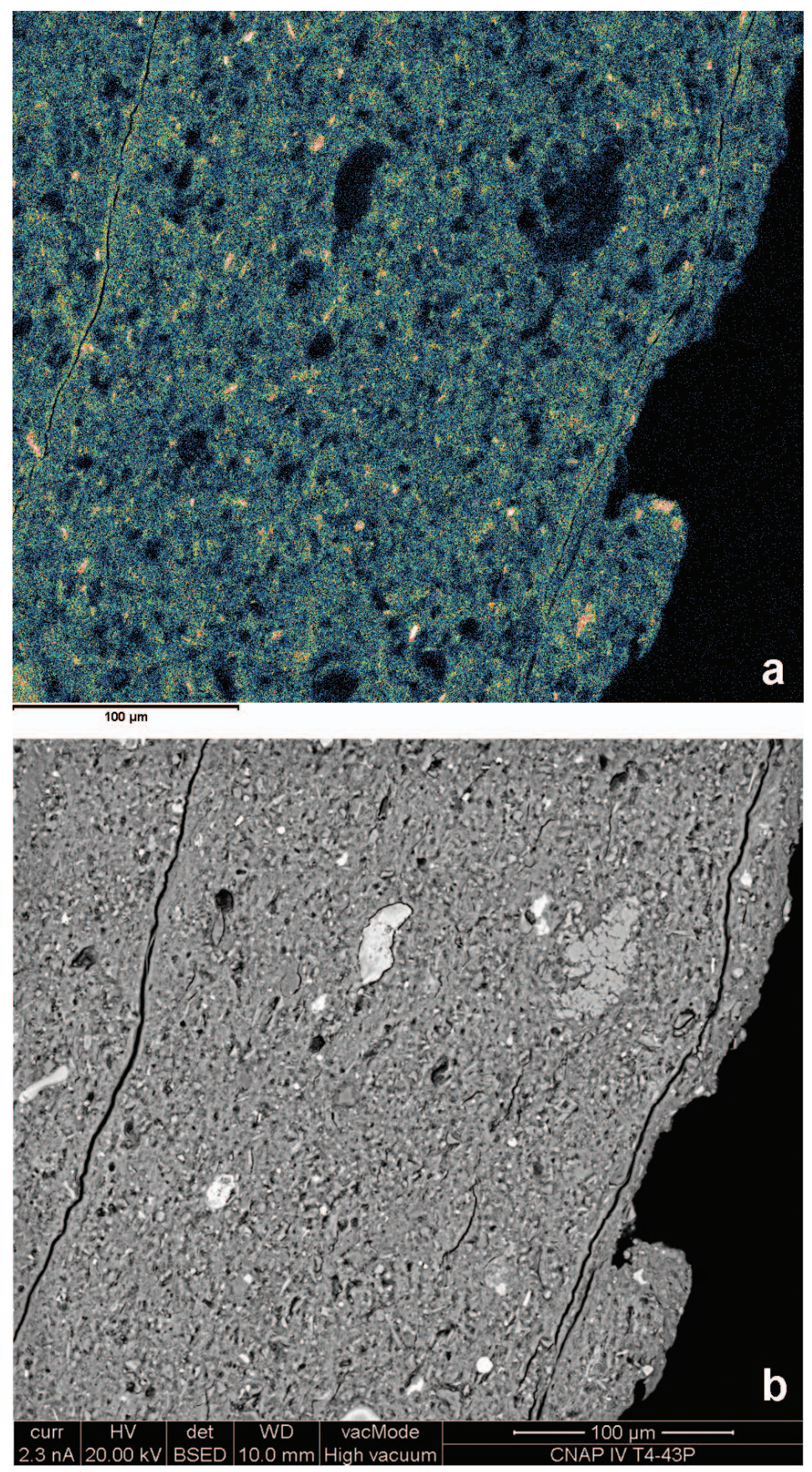

FIG. 7. Sample T4-43P. a (upper image): BSEM image. b (lower image): Mg X-ray map of the same area (lighter colours signify higher $\mathrm{Mg}$ concentration). Sample lamination runs near vertical in the field of view. Two slightly open microfractures run sub-parallel to the bedding. Texturally, these are marked by $5-10 \mu \mathrm{m}$ thick bands of smoother clay (a) that coincide with lines of raised $\mathrm{Mg}$ concentration, shown as brighter areas in the map (b). The $\mathrm{Mg}$ map reveals a thin discontinuous and texturally indistinct line of raised $\mathrm{Mg}$ diverging at an angle of $\sim 30^{\circ}$ as a side branch on the lower part of the upper microfracture. 


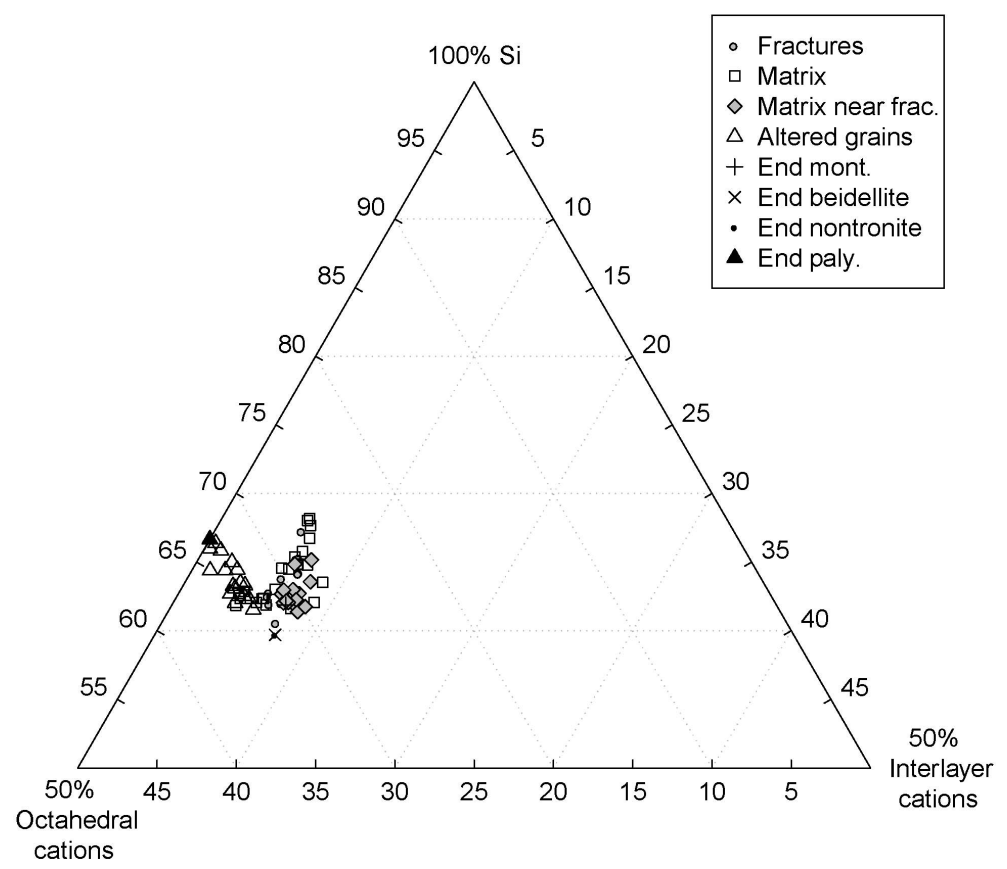

FIG. 8. Triaxial Si-octahedral cations-interlayer cations plot using APFU values. All clay data. End-member dioctahedral smectite and palygorskite points included for reference (Alexander et al., 2011).

tional observations are consistent with the morphological observations from the rock chip portions of the same samples. This difference in alteration product mineralogy between the two samples may reflect the different primary materials, or be due to differences in the timing of the formation of the alteration products or could be due to variations in local micro-environments inducing smectite to palygorskite and palygorskite to smectite alterations (cf. Krekeler et al., 2005).

\section{EVIDENCE FOR GROUNDWATER INTERACTION}

The bentonite at the Parsata site sits directly upon the UPL which is known to contain alkali groundwaters (e.g. from the P1 borehole) and evidence exists for the presence of fossilized bentonite reaction zones in the area (see Alexander \& Milodowski, 2011, for details). A resistivity survey of the site also indicated the presence of groundwaters at shallow depth immediately below Trenches 1 and 4 (Alexander \& Milodowski, 2013), but the base of the trenches were only damp with no flowing groundwater encountered. To assess the likelihood of direct groundwater/bentonite reaction better, uranium series disequilibria and ${ }^{87} \mathrm{Sr} /{ }^{86} \mathrm{Sr}$ ratios were established for groundwater and solid phase samples in the trenches and groundwater boreholes in the area. The uranium series disequilibria results imply groundwater activation and groundwater/rock interaction at the base of the bentonite in the last $10^{5}$ a with rock-groundwater reaction ongoing today in isolated zones. These ages for groundwater/rock reaction are supported by an independent analysis (Pitty et al., 2013) of the regional (Troodos) and local (Parsata) geomorphological evolution over the last $1 \mathrm{Ma}$, which indicated initiation of low-temperature serpentinization reactions (producing alkali groundwaters) in the last $10^{5}$ a.

${ }^{87} \mathrm{Sr} /{ }^{86} \mathrm{Sr}$ ratios indicate reaction with a groundwater which has a mixed signature, composed predominantly of alkaline groundwaters but with a clear signature of material derived from the overlying Lower Lefkara Formation (mainly chalks). This could indicate periodic penetration of surficial waters to depth in the bentonite during cooler, wetter periods (ca. every $21 \mathrm{ka}$ in the eastern Mediterranean; Pitty et al., 2013), but is more likely to be a reflection of groundwater infiltration through the Lower Lefkara Formation 

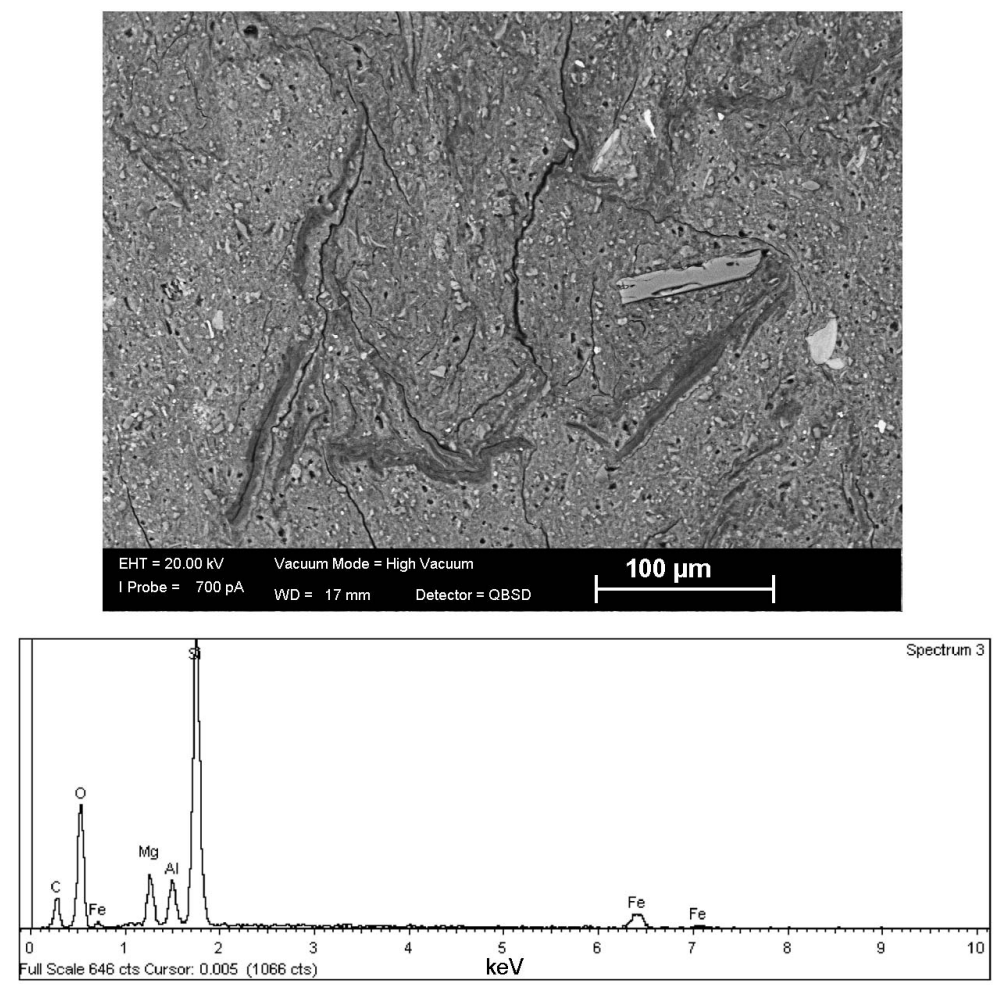

FIG. 9. BSEM image (top) and EDXA spectrum (bottom). Polished section from sample MPLP901 showing micro-fiamme textures. Silt- and sand-sized grains are mostly of plagioclase (pl) and apatite (ap). The EDXA spectrum is from the site marked in the image and is typical of those recorded from this phase. These give chemistries consistent with palygorskite compositions (Alexander et al., 2011).

above Parsata, before reaction in the UPL produces alkali groundwaters.

\section{DISCUSSION}

Although it is difficult to evaluate the temporalfabric relationships between all of the secondary minerals in these very fine-grained rocks, a paragenetic sequence of mineralization and mineralogical alteration has been developed and is illustrated in Fig. 10. Of the five main stages identified, only that pertaining to recent, lowtemperature reaction is discussed here (the details of the rest are covered in Alexander \& Milodowski, 2013).

\section{Late smectite reaction}

XRD patterns from the Parsata bentonites reveal no evidence for the denaturing or decomposition of the montmorillonite component(s). However, detailed SEM observations identified a secondary Mg-rich fibrous clay mineral, with a palygorskitelike composition, to be forming from the surfaces of altering, sheet-like montmorillonite particles. These were exfoliating and breaking down to form the fibrous secondary $\mathrm{Mg}$-rich silicate phase. The relative paragenesis of the palygorskite was difficult to determine unambiguously, but it does appears to be a relatively late-stage alteration product in most samples (especially on fracture surfaces).

The presence of palygorskite in the bentonites of southern Cyprus has been mentioned previously by Gass et al. (1994). Christidis (2006) also described a late-stage partial replacement of smectite by fibrous palygorskite in these deposits, attributed to the interaction of the smectite with Si-rich porewaters produced by the dissolution of siliceous radiolarian frustules facilitated by the circulation of hydrothermal fluids. But this would be a relatively 
PROCESSES

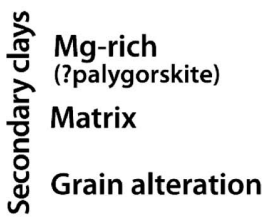

Silica / quartz

Zeolite

Microfracturing

Macrofracturing

Mn oxide / hydroxide

Fe oxide / hydroxide

Calcium Carbonate

Dissolution

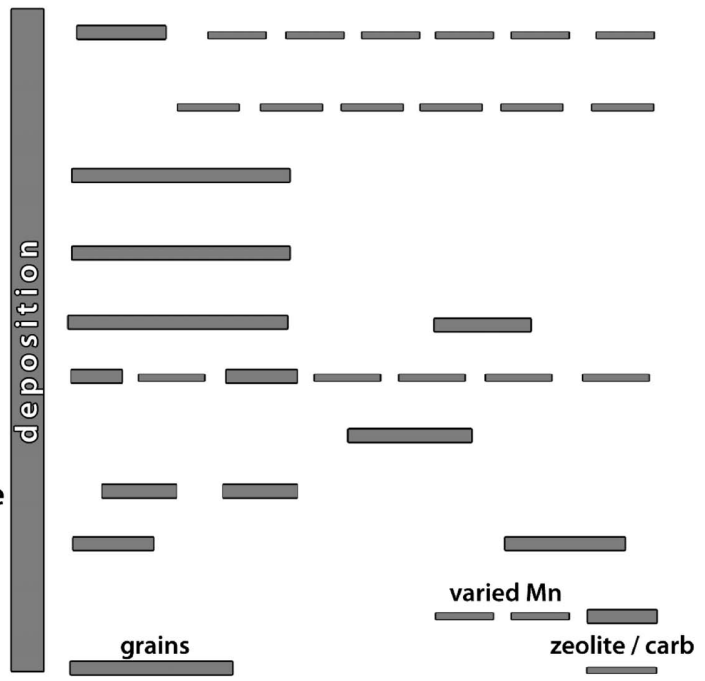

FIG. 10. Proposed bentonite paragenetic sequence (from Alexander \& Milodowski, 2013).

early event and therefore unlikely to be associated with the late-stage palygorskite observed here. Equally, dissolution of amorphous or poorly-crystalline biogenic silica could also occur by interaction with alkaline groundwater, to produce high-Si porewaters that would then lead to smectite alteration.

Palygorskite can also be formed by pedogenic processes, and is found as an authigenic mineral under evaporative conditions, often associated with calcrete formation, in arid environment soils and palaeosols (e.g. Singer, 1991). It is also formed in highly saline, playa and alkaline lake sediments (e.g. Botha \& Hughes, 1992), where it may also form as an alteration product of smectite. The formation of palygorskite in these environments appears to be favoured by the alkaline conditions and high concentration of $\mathrm{Mg}$. The destabilization of smectite and its breakdown to palygorskite in saline/alkaline lake environments is encouraged by increasing $\mathrm{Mg}$ : Ca ratios in the porewater (Botha \& Hughes, 1992).

Secondary palygorskite is associated with lowtemperature serpentinization and alteration of ultrabasic rocks. Authigenic palygorskite has also been described as a reaction product of the interaction of $\mathrm{Mg}$-rich hydrothermal fluids on smectite in deep-sea sediment cores recovered from the Barracuda Escarpment in the western Atlantic, where it is associated with quartz, zeolites and serpentine minerals (Bonatti \& Joensuu, 1968). These authors suggested the following reaction occurs:

montorillonite + silica $+[\mathrm{Ca}$ and $\mathrm{Mg}$ in solution $] \rightarrow$ palygorskite + clinoptilolite

Although it was not possible to define the palygorskite distribution in the Parsata bentonites quantitatively due to the very minor volumes present, qualitative evaluation suggested that palygorskite forms a greater proportion of the clay assemblage in the deepest clay sampled from the trenches. The whole-rock geochemical profile in the Parsata trenches indicates a progressive increase in $\mathrm{Mg}$ with depth through laminated bentonite, with a very sharp increase in both $\mathrm{Mg}$ and $\mathrm{Ca}$ concentration in the highly fractured bentonite immediately above the contact with the UPL. This $\mathrm{Mg}$ enrichment would be consistent with the greater abundance of palygorskite indicated qualitatively by $\mathrm{XRD}$ at the base of the sequence. Ongoing work on new samples (Alexander \& Milodowski, 2013) has confirmed that the palygorskite is restricted to the close viscinity of the UPL.

Whilst this does not conclusively prove that the observed alteration of smectite to palygorskite is the 
result of interaction with alkaline groundwater, it would be consistent with reaction with lowtemperature alkali, Mg-rich, groundwaters associated with serpentinization from the underlying ophiolite assemblage. This is consistent with the natural decay series data which indicate that there has been uptake of uranium from the groundwater throughout the base of the sediment column, indicating ongoing reaction for the last $10^{5}$ a. In particular, samples in Trench 1 and Trench 4 from just above the UPL show evidence of long-term uranium deposition, indicating a zone of long-term groundwater-bentonite reaction.

Low-temperature serpentinization is still ongoing in Cyprus, with relatively young ages reported for the alkali groundwaters of the Kouris valley (Boronina et al., 2005) and the Allas Springs/ Chrisovrysi Springs groundwaters (Alexander et al., 2011), but to understand any potential bentonite reaction, it is also necessary to estimate when it started. Geomorphological evidence presented in Alexander et al. (2011) suggests for the Troodos Massif that this was some $0.8 \mathrm{Ma}$ ago and was probably of a similar date for the Parsata area. This is supported by the above noted natural decay series data which indicate ongoing groundwater-rock reaction in the Parsata area over the last $10^{5}$ a.

Recent mineralogical studies have identified palygorskite-like and sepiolite-like fibrous $\mathrm{Mg}$-rich silicates as alteration products in medium-term (15 a) laboratory batch experiments examining the interaction of "young" (K-, Na-rich) and "evolved" (Ca-rich) alkaine cement porefluids with rock from the Sellafield area of the UK (E.B.A.Moyce, pers. comm., 2011). The original experimental study (Rochelle et al., 1997) reported that, after 2 years, cement phases such as amorphous calcium silicate hydrate (CSH), ettringite and possibly apophyllite were produced as reaction products. Mineralogical observations after 15 years have shown that the early-formed $\mathrm{CSH}$, ettringite and possible apophyllite reaction products are no longer present, dolomite has been extensively dissolved and partially replaced by calcite and the silicate reaction products are now dominated by palygorskite-like Mg-rich silicate. The $\mathrm{pH}$ of the reacting fluid has now been buffered (presumably by reaction with the rock) down to $<9$.

These observations from these medium-term batch experiments suggest that, as the alkaline fluids evolve and reduce in $\mathrm{pH}, \mathrm{Mg}$-rich silicates may be formed. These observations may also provide some indirect evidence for the palygorskite replacement of smectite observed in the bentonites from Parsata. If so, this suggests that these phases could be typical of late (and thus lower $\mathrm{pH}$ ) smectite/alkaline fluid reaction products.

\section{CONCLUSIONS}

CNAP was carried out following identification of the requirement to support ongoing laboratory and modelling efforts on the potential reaction of the bentonite buffer with cementitious leachates in the repository EBS. Although it is known that the higher $\mathrm{pH}$ (12.5 to 13) leachates from OPC cement will degrade bentonite, it is unclear if this will also be the case for the lower $\mathrm{pH}$ (10 to 11) leachates typical of low-alkali cements. Ongoing laboratory and URL programmes which are currently investigating this face the obstacle of very slow kinetics (ECOCLAY, 2005) and the production of shortlived metastable phases, meaning obtaining unambiguous results may take decades (cf. Heikola et al., 2013). This is exacerbated by the limitations of the thermodynamic databases for minerals of interest to models of bentonite/low-alkali cement leachate reaction (e.g. Savage et al., 2010).

The results of the analyses presented here suggest that there has been some form of limited alkaline groundwater reaction with the bentonite. However, ambiguity in some of the boundary conditions (mainly due to sample site access limitations) means that it is not possible to conclude with absolute certainty that the cause of reaction is alkali groundwater. Nevertheless, the alternative thesis, that the presence of palygorskite at the base of the bentonite is due to reaction with Mg-rich hydrothermal fluids, would appear to be unlikely on the basis of mineral textural relationships. As noted in Alexander et al. (2011), two or perhaps three hydrothermal events can be traced in the bentonite, but these are most likely early-stage, sub- and supra-marine processes, whereas the smectite-topalygorskite transformation observed here appears to be a very late-stage event. Certainly, Krekelar et al. (2005) note that primary palygorskite is rare in Mesozoic and older sediments.

Assuming that the presence of the palygorskite is due to alkaline fluid reaction, there are several points worth noting:

(1) The presence of the smectite-to-palygorskite transformation zone at the base of the bentonite is unlikely to be due to surface water reaction. As 
noted above, $\mathrm{Sr}$ isotope signatures suggest reaction with alkaline groundwaters, albeit with some potential mixing from surface waters or, more likely, reaction with chalky sediments during infiltration

(2) The smectite-to-palygorskite transformation zone is confined to a highly limited volume of the bentonite very close to the UPL source of the alkaline groundwaters (i.e. it is seen at the base of the trenches, but not significantly in the shallower reaches of the trenches or drillcores). This could be because the source of reaction (i.e. the alkaline groundwaters) is limited, but this seems unlikely considering the geomorphological and isotopic arguments for groundwater circulation for some $10^{5} \mathrm{a}$

(3) Certainly, climatic models suggest groundwater circulation will not have been continuous for that period, but this seems a long enough period to induce reaction when compared to the 15 years required for the recent laboratory experiments which reported palygorskite secondary phases

(4) It seems possible that the smectite to palygorskite reaction front is self limiting in some form as reaction is confined to limited zones behind fracture faces. While this is not strictly comparable to the 'pore clogging' often reported in reactive transport models (e.g. Savage et al., 2002), it may have the same effect in limiting the reach of any reaction front

In conclusion, therefore, it appears likely that long-term reaction of industrial bentonites by lowalkali cement leachates in a repository is unlikely to impact the favourable properties of the bentonite significantly. In the medium term, it will be possible to compare these conclusions with the results of the ongoing laboratory and URL experiments on bentonite reaction.

\section{ACKNOWLEDGMENTS}

The authors would like to thank their colleagues at the GSD (Cyprus) for all their unstinting help, recommendations and advice throughout the duration of this project. The financial support of the three Project Partners, NDA-RWMD (UK), Posiva (Finland) and SKB (Sweden) is gratefully acknowledged as is the support of L.Krall and D.Svensson (both SKB) during the 2012 field season. AEM, SJK and JCR publish with the permission of the Executive Director of the British Geological Survey (NERC). Finally, the comments of two anonymous reviewers are gratefully acknowledged.

\section{REFERENCES}

Ahonen L., Korkeakoski P., Tiljander M., Kivikoski H. \& Laaksonen R. (2008) Quality Assurance of the Bentonite Material. Posiva Working Report WR 2008-33, Posiva, Eurajoki, Finland.

Alexander W.R. \& Milodowski A.E., editors (2011) Cyprus Natural Analogue Project (CNAP) Phase II Final Report. Posiva Working Report WR 2011-08, Posiva, Eurajoki, Finland.

Alexander W.R. \& Milodowski A.E., editors (2013) Cyprus Natural Analogue Project (CNAP) Phase IV Final Report. Posiva Working Report WR 2013-20, Posiva, Eurajoki, Finland (in press).

Alexander W.R., Arcilla C.A. et al. (2008) A new natural analogue study of the interaction of lowalkali cement leachates and the bentonite buffer. Scientific Basis for Nuclear Waste Management, 31, 493-500.

Alexander W.R., Milodowski A.E. \& Pitty A.F., editors (2011) Cyprus Natural Analogue Project (CNAP) Phase III Final Report. Posiva Working Report WR 2011-77, Posiva, Eurajoki, Finland.

Alexander W.R., McKinley I.G. \& Kawamura H. (2013) The process of defining an optimal natural analogue programme to support national disposal programmes. Proceedings of a Workshop on Natural Analogues for Safety Cases of Repositories in Rock Sal, 4-6 September 2012. Braunschweig, Germany. NEA/OECD, Paris, France (in press).

Alonso J., Garcia-Sineriz J.L. et al. (2009) ESDRED Module 4 Report: Temporary Sealing Technology, Final Technical Report. EC Report, EC, Luxembourg.

Barnes I. \& O’Neill J.R. (1969) The relationship between fluids in some fresh alpine-type ultramafics and possible modern serpentinisation, western United States. Geological Society of America Bulletin, 80, 1947-1960.

Bear L.M. (1960) The Geology and Mineral Resources of the Akaki-Lythrodondha Area. Geological Survey Department Memoirs No. 3, GSD, Lefkosia, Cyprus.

Bonatti E. \& Joensuu O. (1968) Palygorskite from Atlantic deep sediments. American Mineralogist, 53, 975-983.

Boronina A.V., Balderer W., Renard P. \& Stichler W. (2005) Study of stable isotopes in the Kouris catchment (Cyprus) for the description of the regional groundwater flow. Journal of Hydrology 308, 214-226.

Botha G. \& Hughes J.C. (1992) Pedogenic palygorskite and dolomite in a late Neogene sedimentary succession, northwestern Transvaal, South Africa. Geoderma, 53, 139-154.

Bradbury M.H. \& Baeyens B. (2002) Porewater Chemistry in Compacted, Re-saturated MX-80 Bentonite: Physico-Chemical Characterisation and 
Geochemical Modelling. PSI Report 02-10, PSI, Villigen, Switzerland.

Chapman N.A., McKinley I.G. \& Smellie J.A.T. (1984) The Potential of Natural Analogues in Assessing Systems for Deep Disposal of High-Level Radioactive Waste. Nagra Technical Report NTB 85-41, Nagra, Wettingen, Switzerland.

Christidis G.E. (2006) Genesis and compositional heterogeneity of smectites. Part III: Alteration of basic pyroclastic rocks - a case study from the Troodos Ophiolite Complex, Cyprus. American Mineralogist, 91, 685-701.

ECOCLAY (2005) ECOCLAY II: Effects of Cement on Clay Barrier Performance - Phase II. EC Nuclear Science and Technology Final Report EUR 21921, EC, Luxembourg.

Gass I.D., MacCleod C.J., Murton B.J., Panayiotou A., Simonian K.O. \& Xenophontos C. (1994) The Geology of the Southern Troodos Transform Fault Zone. Geological Survey Department Memoir no.9, GSD, Lefkosia, Cyprus.

Heikola T., Kumpulainen S., Vuorinen U., Kiviranta L. \& Korkeakoski P. (2013) Influence of alkaline $(\mathrm{pH}$ $8.3-12.0)$ and saline solutions on chemical, mineralogical and physical properties of two different bentonites - batch experiments at 25 and $60^{\circ} \mathrm{C}$. Clay Minerals, 48, $\mathrm{xxx}-\mathrm{xxx}$.

Hillier S., Suzuki K. \& Cotter-Howells J. (2001) Quantitative determination of cerussite (lead carbonate) by X-ray powder diffraction and inferences for lead speciation and transport in stream sediments from a former lead mining area of Scotland. Applied Geochemistry, 16, 597-608.

Krekeler M.P.S., Hammerley E., Guggenheim S. \& Rakovan J. (2005) Microscopy studies of the palygorskite to smectite transformation. Clays and Clay Minerals, 53, 92-99.

Metcalfe R. \& Walker C. (2004) Proceedings of the International Workshop on Bentonite-Cement Interaction in Repository Environments 14-16 April 2004, Tokyo, Japan. NUMO Technical Report NUMO-TR-04-05, NUMO, Tokyo, Japan.

Miller W.M., Alexander W.R., Chapman N.A., McKinley I.G. \& Smellie J.A.T. (2000) Geological Disposal of Radioactive Wastes and Natural Analogues. Waste management series, 2, Pergamon, Amsterdam, The Netherlands.

NDA (2010) Geological Disposal: Near Field Evolution Status Report. NDA Report No. NDA/RWMD/033. NDA-RWMD, Harwell, UK.

Neal C. \& Shand P. (2002) Spring and surface water quality of the Cyprus Ophiolites. Hydrology and
Earth System Sciences, 6, 797-817.

Neaman A., Pelletier M. \& Villieras F. (2003) The effects of exchanged cation, compression, heating and hydration on textural properties of bulk bentonite and its corresponding purified montmorillonite. Applied Clay Science, 22, 153-168.

Pitty A.F., MacKenzie A.B., Milodowski A.M. \& Alexander W.R. (2013) Dating the initiation of groundwater circulation: an example from the Troodos Massif, Cyprus. Geomorphology (in preparation).

Rochelle C.A., Pearce J.M., Bateman K., Coombs P. \& Wetton P.D. (1997) The evaluation of chemical mass transfer in the disturbed zone of a deep geological disposal facility for radioactive wastes. X: Interaction between synthetic cement porefluids and BVG: Observations from experiments of 4, 9 and 15 months duration. British Geological Survey (BGS), Fluid Processes and Waste Management Group Report, WE/97/16C, 79pp. BGS, Keyworth, UK.

Rozalen M., Huertas F.J. \& Brady P.V. (2009) Experimental study of the effect of $\mathrm{pH}$ and temperature on the kinetics of montmorillonite dissolution. Geochimica et Cosmochimica Acta, 73, 3752-3766.

Savage D. \& Benbow S. (2007) Low pH Cements. SKI Report 2007:32. Swedish Radiation Safety Authority (SSM), Stockholm, Sweden.

Savage D., Noy D. \& Mihara M. (2002) Modelling the interaction of bentonite with hyperalkaline fluids. Applied Geochemistry, 17, 207-223.

Savage D., Arthur R., Watson C. \& Wilson J. (2010) An Evaluation of Models of Bentonite Pore Water Evolution. Swedish Radiation Safety Authority (SSM) Report 2010-12, SSM, Stockholm, Sweden.

Sellin P., Karlsson F., Werme L., Spahiu K. \& Puigdomenech I. (2003) Effect of $\mathrm{pH}$ on the safety of KBS-3 deep repository and the confidence in safety assessments. Proceedings of a Workshop on Qualification of Low pH Cement for a Geological Repository, Oct 15-16, 2003, Stockholm. SKB, Stockholm, Sweden.

Singer A. (1991) Palygorskite in sediments: Detrital, diagenetic or neoformed - A critical review. Geologische Rundschau, 68, 996-1008.

Wilson J., Savage D., Bond A., Watson S., Pusch R. \& Bennett D. (2011) Bentonite: a Review of Key Properties, Processes and Issues for Consideration in the UK Context. Quintessa Report QRS-1378ZG1.1 for the NDA-RWMD, Quintessa, Henley-onThames, Oxfordshire, UK. 